\title{
The welfare of slow growing broiler genotypes reared in organic system
}

\author{
Hasan Eleroğlu' ${ }^{1 *}$, Arda Yıldırım², Mustafa Duman³, Ahmet Şekeroğlu ${ }^{4}$ \\ ${ }^{1}$ Şarkışla Aşık Veysel Vocational High School, Cumhuriyet University, Sivas, Turkey; ${ }^{2}$ Department of Animal Science, Agriculture Faculty, \\ Gaziosmanpaşa University, Tokat, Turkey; ${ }^{3}$ Bor Vocational High School, University of Niğde, Niğde/Turkey; ${ }^{4}$ Department of Animal Production \\ and Technologies, Agricultural Sciences and Technologies Faculty, Niğde University, Niğde, Turkey
}

\section{A B S T R A C T}

\begin{abstract}
This study was conducted to compare welfare indicators and some serum biochemical parameters of two different slow-growing genotypes (Hubbard S757; S757 and Hubbard Grey Barred JA; GB-JA) under organic housing system. A total of 240 day-old chicks were allocated randomly into 2 experimental group with 6 replicates and 20 chicks was reared in each replicate. The tonic immobility was a significant difference between genotypes and sex at 10 and 14 weeks, respectively $(P<0.05)$. Overall duration of tonic immobility was similar $(P>0.05)$ in genotypes and sex. The effect of sex was significant for width of tarsometatarsus at the joint with tibiotarsus; males had greater fluctuating and relativite asymmetry than females $(P<0.05)$. There were positively correlations between fluctuating and relative asimetry values of the third phalanx of the mid toe length and the fourth phalanx of the outer toe length from specific feet trait measurements. Serum cholesterol and uric acid had significant differences between genotypes $(P<0.01)$. Cholesterol levels was significantly $(P<0.01)$ higher in male than in female slow-growing broiler. It is concluded that slow-growing genotypes and sex had no effect on measures of welfare, such as the fluctuating asymmetry, relativite asymmetry, tonic immobility and rectal temperatures.
\end{abstract}

Keywords: Fluctuating asymmetry; Organic production; Serum biochemical; Slow-growing broiler; Tonic immobility; welfare indicator

\section{INTRODUCTION}

Under organic housing systems, chickens are faced with a rich environment and perform more behavioural repertories than in cages housing, all of which may improve animal welfare. Besides, they are subjected to various factors as well as infectious and parasitic diseases, social interactions and unfavourable climatic conditions that may expand both stress and fear reactions and depress wellbeing. As criteria for measuring levels of stress, welfare and fear in chickens is predicted to duration of tonic immobility (TI) and fluctuating asymmetry (FA) (Campo et al., 2008; Dávila et al., 2011).

As it is known, the right and left sides of any morphological character are expected to be equal during growth or exhibit a similar growth in symmetric animals. Many factors such as genetically structures, rearing and the other environmental conditions of the animals are shaped the situation (Campo et al., 2005b; Mendeş, 2008). Environmental stress such as stocking density, lighting and feeding programs may affect developmental stability, thus, it can be seen increasing variation between individuals in the poultry housing systems (Mendeş, 2008; Møller et al., 1995; Møller et al., 1999). Housing systems and gender are important for chicken welfare. The morphology of two sides of a bilateral character largely develops under identical environmental conditions, alterations between right and left are presumed to reflect developmental unstability. FA can be considered as deviations from perfect symmetry. It may benefit in determining the suitability of breeding conditions as experienced by animals during their growing (Van Nuffel et al., 2007). FA has been claimed to be positively related to TI by Campo et al. (2000). On the other hand, such shortterm differences could contain principal information about changes in the environment of an individual. Bizeray et al. (2002) have reported that increased activity may potentially improve leg condition performance and reduce the level of fearfulness in birds. Tuyttens et al. (2008) stated that broilers from conventional farms reveal more FA than broilers from organic farms, and recommend that, in despite of the potentially raised up risk of immunological challenge, bird welfare is usually superior in organic farms as compared with conventional farms in Belgium. 
The objective of this study is therefore to compare two slow-growing genotypes and sex reared broilers organically with regards to a wide variety of animal-related welfare indicators such as duration of the TI, a traditional measure of fearfulness in poultry; FA and relativite asymmetry (RA), a measure that has been reported to reflect chronic stress and welfare status and some serum biochemical profile.

\section{MATERIALS AND METHODS}

Two hundred and forty slow-growing chickens (mixed-sex) consisting of equal number of Hubbard S757 (S757) and Hubbard Grey Barred JA (GB-JA) strains were utilized for the investigation under organic system. In the study, day-old chicks were weighed, identified with a wing number and randomly allocated to two treatments with six replications in two-way ANOVA. The experiment was approved by the Ethics Committee of the Cumhuriyet University (20.06.2011/50).

There were twelve portable shelters $(1.5 \times 1.5 \mathrm{~m})$, each containing 20 birds per replication with 10 birds $/ \mathrm{m}^{2}$ stocking density placed in each of the $100 \mathrm{~m}^{2}$ grazing area. The research was carried out according to the principles and implementation of regulation on organic agriculture (OFL, 2010) published by the Republic of Turkey, Ministry of Food, Agriculture and Livestock. The experiment was ended at the end of the $14^{\text {th }}$ week. Birds were fed a three-phase organic diet ad-libitum: a starter diet (197 g crude protein (CP)/ kg and 13.00 MJ of metabolizable energy (ME) per kg of diet) from 0 to 28 days; a grower diet $(201 \mathrm{~g} / \mathrm{kg} \mathrm{CP}$ and $12.72 \mathrm{MJ}$ of ME per kg of diet) from 29 to 81 days and a finisher diet $(180 \mathrm{~g} / \mathrm{kg} \mathrm{CP}$ and $12.91 \mathrm{MJ}$ of ME per $\mathrm{kg}$ of diet) from 82 to 98 days. Creating artificial poultry pasture, Lotus corniculatus (50\%) and Bromus inermis (50\%) are used by mixing (Eleroğlu et al., 2014a).

The eighteen male and eighteen female chickens from each group selected a total of 72 chickens were tested for TI. The TI reactions were examined in 6,10 and 14 weeks old birds benefiting from the wing numbers. The TI was induced by placing birds in a U-shaped wooden cradle covered with a cloth and restraining them for 15 seconds, as reported by Jones and Faure (1981). The duration of TI was recorded (i.e. the time until the bird stood up). If an attempt of induction was unsuccessful (no TI or TI lasting less than $10 \mathrm{~s}$ ), the experimenter immediately resumed the induction procedure. If TI could not be induced after five attempts, the bird was deemed not to be susceptible and its TI duration score was $0 \mathrm{~s}$. If the bird did not stand after $10 \mathrm{~min}$, a maximum score of $600 \mathrm{~s}$ was recorded for TI duration (Dávila et al., 2011; Campo and Prieto, 2009). In the present study, after TI tested, the responses of rectal temperatures (RT) of slow-growing broilers were measured. The RT was measured with a manual electronic thermometer $\left( \pm 0.1^{\circ} \mathrm{C}\right)$ in 6,10 and 14 weeks by inserting into the rectum $3 \mathrm{~cm}$ in depth for each bird. Thermometer until it is fixed measurement the chicken was gently handled.

The twelve male and twelve female slow-growing chickens from each group selected a total of 48 chickens were slaughtered and after tested for asymmetry measurements. FA and RA were used as measures for deviation from bilateral symmetry. The measured morphological traits were both right $(\mathrm{R})$ and left $(\mathrm{L})$ outer, middle, inner, and hind toe, and leg (metatarsus) lengths, and tarsometatarsus widths areas $(A=$ length of the third phalanx of the mid toe, $\mathrm{B}=$ length of the fourth phalanx of the outer toe, $\mathrm{C}=$ length of the back toe, $\mathrm{D}=$ length of tarsometatarsus, $\mathrm{E}=$ width of tarsometatarsus at the spur, $\mathrm{F}=$ width at $1 \mathrm{~cm}$ above the spur of tarsometatarsus and $\mathrm{G}=$ width of tarsometatarsus at the joint with tibiotarsus). Right and left side values of a bird were taken during the same session. All bilateral 5 lengths and 2 tarsometatarsus widths were measured (Van Nuffel et al., 2007) in millimeter by using a digital caliper (to the nearest $0.01 \mathrm{~mm}$ ). FA for a trait was defined by the unsigned or absolute differences between sides [|R-L $\mid]$; the unsigned value as an index of $\mathrm{FA}$ (equivalent to the mean deviation) was more appropriate for these data than indices using the variance of right minus left sides (Campo et al., 2005b). A series of steps was followed before identifying exhibited asymmetry as FA (normal distribution of signed right minus left differences with a mean of zero). RA was defined as the ratio of the absolute value of asymmetry $(\mathrm{L}-\mathrm{R})$ over bilateral traits: $\mathrm{RA}=(|\mathrm{L}-\mathrm{R}| /[(\mathrm{L}+\mathrm{R}) / 2]) \mathrm{x}$ 100 (Yang, 1998).

Before slaughter process, about $5 \mathrm{~mL}$ blood samples were collected from the experimental birds. At the ages of 98 days (48 birds) blood was collected by venipuncture of the wing vein (Vena cutanea ulnaris), kept on ice and transferred to the laboratory (Eleroğlu et al., 2014b). Serum was separated and used for biochemical assays. The concentration of serum glucose, cholesterol, total protein, uric acid, $\mathrm{Ca}, \mathrm{P}, \mathrm{Na}, \mathrm{K}$ and $\mathrm{Cl}$ were measured, using commercial kits on an auto-analyzer (Technicon RA-1000). The statistical analysis was conducted using the SPSS 16.0 (Inc. Chicago. IL. USA) program. Treatment effects were considered to be significant at $\mathrm{P}<0.05$. Data were expressed as mean values with pooled standard errors (standard errors of the mean, SEM). 


\section{RESULTS}

Mean values indicating the comparison of genotype and sex on the TI, number of tonic immobility induction (NTI) and $\mathrm{RT}$ are summarized in Table 1.

Slow-growing genotypes housed in organic system were similar duration of TI for 6 and 14 weeks. Likewise, the genotypes had no effect on the NTI at 6,10 and 14 weeks. The TI had significant difference between genotypes at 10 weeks $(\mathrm{P}<0.01)$. The average tonic immobility duration of S757 genotype was higher than that GB-JA genotype (67.53 vs. 44.79 s) at 10 weeks. However, the observed difference between male and female in 14 weeks was significant $(\mathrm{P}<0.05)$.

Table 2 is summarized the data concerning the FA and RA. There was not a significant difference $(\mathrm{P}>0.05)$ in the FA and RA of A, B, C, D, E and F values between genotypes, sex and their interaction except FA value of $G$ in terms of sex. Some serum blood parameters of two different slow-growing broiler genotypes reared organic system are summarized in Table 3. It has seen that genotypes and sex did not affect on serum glucose, total protein, $\mathrm{Cl}, \mathrm{Na}$, $\mathrm{K}, \mathrm{P}, \mathrm{Ca}$ levels, except uric acid ( $\mathrm{P}>0.05)$. Cholesterol and uric acid has significant differences between genotypes $(\mathrm{P}<0.01)$. It is seen that only $\mathrm{FA}$ of $\mathrm{A}$ is significantly correlated with $\mathrm{FA}$ of $\mathrm{B}(\mathrm{P}<0.05)$, whereas $\mathrm{FA}$ of $\mathrm{E}$ is significantly correlated with $\mathrm{FA}$ of $\mathrm{G}$ (Table 4; $\mathrm{P}<0.05$ ). Likewise, there is an association between the RA of $A$ and RA of B (Table 4; $\mathrm{P}<0.05)$.

\section{DISCUSSION}

As can be seen from Table 1, slow-growing male broilers showed more fear stress than those female broilers (average TI 51.89 vs. 34.46 s) at 14 weeks of age. Overall TI and NTI were similar $(\mathrm{P}>0.05)$ in genotypes and sex. Some study showed that genotypes had considerable variations in terms of TI (Campo et al., 2000). In the present study TI of slow-growing broilers had excessively lower (ranged 57.70 to $93.77 \mathrm{~s}$ ) with outdoor access than those (ranged 158 to 398 s) of Campo et al. (2008), who tested six different Spanish breeds. Likewise, Prieto and Campo (2010) stated that TI found $99 \mathrm{~s}$ in White Leghorn reared with standard temperatures.

The result of present study showed that the responses of RT was not affected by genotypes, sex and their interaction (Table 1; P>0.01). RT is one of the most important

Table 1: The tonic immobility reaction and rectal temperature response $\left({ }^{\circ} \mathrm{C}\right)$ of two different slow-growing broiler genotypes reared organic system

\begin{tabular}{|c|c|c|c|c|c|c|c|c|c|c|c|c|c|}
\hline \multicolumn{2}{|l|}{ Items } & \multicolumn{3}{|c|}{6 weeks } & \multicolumn{3}{|c|}{10 weeks } & \multicolumn{3}{|c|}{14 weeks } & \multicolumn{3}{|c|}{ Overall } \\
\hline $\mathbf{G}^{1}$ & $S^{2}$ & $\mathrm{TI}^{3}$ & $\mathrm{NTI}^{4}$ & $\mathbf{R T}^{5}$ & $\mathrm{TI}^{3}$ & $\mathrm{NTI}^{4}$ & $\mathbf{R T}^{5}$ & $\mathrm{Tl}^{3}$ & $\mathrm{NTI}^{4}$ & $\mathbf{R T}^{5}$ & $\mathrm{TI}^{3}$ & $\mathrm{NTI}^{4}$ & $\mathbf{R T}^{5}$ \\
\hline \multirow{2}{*}{$\begin{array}{l}\text { GB- } \\
\text { JA }\end{array}$} & $F$ & 103.33 & 1.53 & 41.73 & 38.27 & 1.88 & 41.84 & 31.50 & 1.59 & 41.63 & 57.70 & 1.67 & 41.73 \\
\hline & M & 158.00 & 1.32 & 41.81 & 51.30 & 1.63 & 41.93 & 46.15 & 1.44 & 41.69 & 85.15 & 1.48 & 41.81 \\
\hline \multirow[t]{2}{*}{ S757 } & $\mathrm{F}$ & 185.88 & 1.32 & 41.77 & 58.02 & 1.74 & 41.83 & 37.41 & 1.26 & 41.71 & 93.77 & 1.44 & 41.77 \\
\hline & M & 126.11 & 1.12 & 41.75 & 77.04 & 1.53 & 41.80 & 57.62 & 1.18 & 41.70 & 86.92 & 1.27 & 41.75 \\
\hline $\mathrm{SEM}^{6}$ & & 18.14 & 0.071 & 0.206 & 4.374 & 0.096 & 0.029 & 4.313 & 0.078 & 0.038 & 6.72 & 0.067 & 0.026 \\
\hline Genotype & & NS & NS & NS & $\star *$ & NS & NS & NS & NS & NS & NS & NS & NS \\
\hline Sex & & NS & NS & NS & NS & NS & NS & * & NS & NS & NS & NS & NS \\
\hline${ }^{7} \mathrm{G} \times \mathrm{S}$ & & NS & NS & NS & NS & NS & NS & NS & NS & NS & NS & NS & NS \\
\hline
\end{tabular}

${ }^{1} \mathrm{~GB}-\mathrm{JA}=$ Hubbard Grey Barred JA; S757 = Hubbard S757, ${ }^{2} \mathrm{~F}=$ Female; M: Male, ${ }^{3} \mathrm{TI}=$ Tonic immobility, ${ }^{4} \mathrm{NTI}=\mathrm{Number}$ of tonic immobility induction, ${ }^{5} \mathrm{RT}=\mathrm{Rectal}$ temperature, ${ }^{6}$ Standard error of the mean, ${ }^{7}$ Genotype $x$ Sex, ${ }^{*} \mathrm{P}<0.05 ;{ }^{* *} \mathrm{P}<0.01 ; \mathrm{NS}, \mathrm{P}>0.05$

Table 2: Fluctuating and relative asymmetry of two slow-growing broiler genotypes reared organic system

\begin{tabular}{|c|c|c|c|c|c|c|c|c|c|c|c|c|c|c|c|}
\hline \multicolumn{2}{|c|}{ Items } & \multicolumn{14}{|c|}{ Fluctuating asymmetry (FA) and relative asymmetry (RA) } \\
\hline \multirow[t]{2}{*}{$\mathbf{G}^{1}$} & \multirow[t]{2}{*}{$\mathbf{S}^{2}$} & \multicolumn{2}{|c|}{$A^{3}$} & \multicolumn{2}{|c|}{$\mathrm{B}^{4}$} & \multicolumn{2}{|c|}{$\mathbf{C}^{5}$} & \multicolumn{2}{|c|}{$\mathrm{D}^{6}$} & \multicolumn{2}{|c|}{$E^{7}$} & \multicolumn{2}{|c|}{$\mathbf{F}^{8}$} & \multicolumn{2}{|c|}{$\mathbf{G}^{9}$} \\
\hline & & FA & RA & FA & RA & FA & RA & FA & RA & FA & RA & FA & RA & FA & RA \\
\hline \multirow[t]{2}{*}{ GB-JA } & $\mathrm{F}$ & 0.69 & 0.76 & 0.62 & 1.06 & 0.71 & 1.75 & 1.89 & 1.20 & 0.93 & 3.11 & 0.63 & 2.41 & 0.83 & 1.77 \\
\hline & $\mathrm{M}$ & 1.03 & 0.97 & 0.93 & 1.42 & 0.78 & 1.67 & 2.51 & 1.44 & 1.03 & 3.13 & 0.66 & 2.24 & 1.39 & 3.52 \\
\hline \multirow[t]{2}{*}{ S757 } & $F$ & 0.89 & 0.94 & 0.53 & 0.90 & 1.20 & 2.77 & 2.19 & 1.33 & 0.51 & 1.64 & 0.48 & 1.71 & 0.67 & 1.40 \\
\hline & $M$ & 0.71 & 0.62 & 0.75 & 1.10 & 1.00 & 1.99 & 1.82 & 0.94 & 1.14 & 3.02 & 0.72 & 2.44 & 1.71 & 3.80 \\
\hline SEM $^{10}$ & & 0.09 & 0.10 & 0.81 & 0.13 & 0.13 & 0.28 & 0.28 & 0.16 & 0.12 & 0.35 & 0.07 & 0.28 & 0.20 & 0.43 \\
\hline Genotype & & NS & NS & NS & NS & NS & NS & NS & NS & NS & NS & NS & NS & NS & NS \\
\hline Sex & & NS & NS & NS & NS & NS & NS & NS & NS & NS & NS & NS & NS & * & * \\
\hline${ }^{11} G \times S$ & & NS & NS & NS & NS & NS & NS & NS & NS & NS & NS & NS & NS & NS & NS \\
\hline
\end{tabular}

${ }^{1} \mathrm{~GB}-\mathrm{JA}=$ Hubbard Grey Barred JA, S757= Hubbard S757 ${ }^{2} \mathrm{Sex}, \mathrm{F}=$ Female; $\mathrm{M}=$ Male, ${ }^{3} \mathrm{~A}=$ Length of the third phalanx of the mid toe, ${ }^{4} \mathrm{~B}=\mathrm{Length}$ of the fourth phalanx of the outer toe, ${ }^{5} \mathrm{C}=$ Length of the back toe, ${ }^{6} \mathrm{D}=$ Length of tarsometatarsus, ${ }^{7} \mathrm{E}=$ Width of tarsometatarsus at the spur, ${ }^{8} \mathrm{~F}=\mathrm{Width}$ at $1 \mathrm{~cm}$ above the spur of tarsometatarsus, ${ }^{9} \mathrm{G}=$ Width of tarsometatarsus at the joint with tibiotarsus, ${ }^{10}$ Standard error of the mean, ${ }^{11} \mathrm{Genotype} \mathrm{X}$ Sex, ${ }^{*} \mathrm{P}<0.05$; NS, P>0.05 
Eleroğlu, et al.: The welfare of broiler in organic system

Table 3: Some serum blood parameters of two slow-growing broiler genotypes reared organic system

\begin{tabular}{|c|c|c|c|c|c|c|c|c|c|c|}
\hline \multicolumn{2}{|c|}{ Items } & \multirow{2}{*}{$\begin{array}{l}\text { Glucose } \\
\mathrm{mg} / \mathrm{dL}\end{array}$} & \multirow{2}{*}{$\begin{array}{l}\text { Cholesterol } \\
\text { mg/dL }\end{array}$} & \multirow{2}{*}{$\begin{array}{l}\text { Uric acid } \\
\mathrm{mg} / \mathrm{dL}\end{array}$} & \multirow{2}{*}{$\begin{array}{c}\text { Total } \\
\text { protein } \mathrm{g} / \mathrm{dL}\end{array}$} & \multirow{2}{*}{$\begin{array}{c}\mathrm{Cl} \\
\mathrm{mg} / \mathrm{dL}\end{array}$} & \multirow{2}{*}{$\begin{array}{c}\mathrm{Na} \\
\mathrm{mg} / \mathrm{dL}\end{array}$} & \multirow{2}{*}{$\begin{array}{c}\mathrm{K} \\
\mathrm{mg} / \mathrm{dL}\end{array}$} & \multirow{2}{*}{$\begin{array}{c}P \\
\mathrm{mg} / \mathrm{dL}\end{array}$} & \multirow{2}{*}{$\begin{array}{c}\mathrm{Ca} \\
\mathrm{mg} / \mathrm{dL}\end{array}$} \\
\hline Genotype $^{1}$ & $\operatorname{Sex}^{2}$ & & & & & & & & & \\
\hline \multirow[t]{2}{*}{ GB-JA } & $\mathrm{F}$ & 242.25 & 97.59 & 5.01 & 3.31 & 119.75 & 156.34 & 5.85 & 7.04 & 9.59 \\
\hline & $M$ & 254.67 & 104.84 & 5.56 & 3.16 & 115.67 & 153.17 & 5.49 & 6.82 & 9.29 \\
\hline \multirow[t]{2}{*}{ S757 } & $\mathrm{F}$ & 233.80 & 104.80 & 3.67 & 3.24 & 118.00 & 153.80 & 5.45 & 6.53 & 9.36 \\
\hline & M & 245.20 & 120.87 & 4.35 & 3.16 & 120.14 & 158.79 & 5.82 & 6.68 & 9.44 \\
\hline SEM $^{3}$ & & 3.45 & 2.31 & 0.228 & 0.056 & 1.033 & 1.36 & 0.168 & 0.097 & 0.109 \\
\hline Genotype & & NS & $* *$ & ** & NS & NS & NS & NS & NS & NS \\
\hline Sex & & NS & $* *$ & NS & NS & NS & NS & NS & NS & NS \\
\hline${ }^{4} \mathrm{G} \times \mathrm{H}$ & & NS & NS & NS & NS & NS & NS & NS & NS & NS \\
\hline
\end{tabular}

${ }^{1} \mathrm{~GB}-\mathrm{JA}=$ Hubbard Grey Barred JA; S757 = Hubbard S757, ${ }^{2} \mathrm{~F}=$ female; $\mathrm{M}=$ male, ${ }^{3}$ Standard error of the mean, ${ }^{4}$ Genotype $\mathrm{X}$ Herb, ${ }^{* *} \mathrm{P}<0.01$; NS, $\mathrm{P}>0.05$

Table 4: Multivariate correlation coefficients between selected morphological FA parameters

\begin{tabular}{|c|c|c|c|c|c|c|c|c|c|c|c|c|}
\hline & \multicolumn{2}{|c|}{$\mathbf{A}^{1}$} & \multicolumn{2}{|c|}{$B^{2}$} & \multicolumn{2}{|c|}{$C^{3}$} & \multicolumn{2}{|c|}{$\mathrm{D}^{4}$} & \multicolumn{2}{|c|}{$E^{5}$} & \multicolumn{2}{|c|}{$F^{6}$} \\
\hline & FA & RA & FA & RA & FA & RA & FA & RA & FA & RA & FA & RA \\
\hline$B^{2}$ & $0.30^{*}$ & $0.29^{*}$ & & & & & & & & & & \\
\hline $\mathrm{C}^{3}$ & 0.09 & 0.08 & -0.16 & -0.18 & & & & & & & & \\
\hline $\mathrm{D}^{4}$ & -0.26 & -0.26 & -0.26 & -0.22 & 0.13 & 0.12 & & & & & & \\
\hline$E^{5}$ & 0.01 & 0.03 & -0.28 & -0.27 & -0.10 & -0.13 & 0.133 & 0.116 & & & & \\
\hline $\mathrm{F}^{6}$ & 0.16 & 0.08 & -0.20 & -0.13 & 0.05 & -0.04 & -0.005 & -0.036 & 0.197 & 0.136 & & \\
\hline $\mathrm{G}^{7}$ & 0.18 & -0.20 & 0.14 & -0.10 & 0.10 & -0.10 & -0.142 & -0.191 & $0.332^{*}$ & 0.021 & 0.057 & 0.035 \\
\hline
\end{tabular}

${ }^{1} \mathrm{~A}=$ Length of the third phalanx of the mid toe, ${ }^{2} \mathrm{~B}=$ Length of the fourth phalanx of the outer toe, ${ }^{3} \mathrm{C}=$ Length of the back toe, ${ }^{4} \mathrm{D}=$ Length of tarsometatarsus, ${ }^{5} \mathrm{E}=$ Width of tarsometatarsus at the spur, ${ }^{6} \mathrm{~F}=$ Width at $1 \mathrm{~cm}$ above the spur of tarsometatarsus, ${ }^{7} \mathrm{G}=$ Width of tarsometatarsus at the joint with tibiotarsus, ${ }^{*} \mathrm{P}<0.05$

physiological responses that reflect the thermoregulation of animal body, and has been suggested to be an indicator of the level of heat stress in broiler chickens (Deeb and Cahaner, 1999). When the broiler chickens are exposed to high temperature, the RT will be elevated, because of the increased heat accumulation (Lin et al., 2004). Slowgrowing broilers are recognized to be less sensitive to heat (Washburn et al., 1980). Several researchers (Deeb and Cahaner, 2001; N'dria et al., 2007) stated that internal heat production in hot conditions in broilers is known to be higher than in slow-growing genotypes. However, broilers rectal temperature was higher under the hot condition, thus resulting in greater body temperature variation (N'dria et al., 2007). According to this result easily understood that the slow-growing broiler genotypes were not exposed to heat stress under organic system. The physiological reactions of the slow-growing broilers animals in terms of level of rectal temperature is in accordance with the results of N'dria et al. (2007) in similar study for the normal environmental temperature.

The degree of relative FA varied among traits. This variation among traits suggests the convenience of a mean RA from multiple traits as a reliable measure of developmental stability (Campo et al., 2000). Mean RA showed that genotypes had similar developmental stability. This finding agrees with Campo et al. (2005b) and Campo et al. (2000) who reported that the differences in FA and RA among genotypes were not significant for leg length (metatarsus) in males and females under conventional systems. Females and males showed similar degrees of FA and RA in six morphological traits, whereas the sex differed for their degree of FA in G at 14 weeks of age. Males showed significantly greater average FA and RA for $G$ than females (1.55 vs. 0.75 and 3.66 vs. 1.59$)$. It has been displayed that females prefer males with symmetric sexual attributes (Møller, 1992), and there is evidence of natural selection for symmetrical attributes in poultry (Campo et al., 2005b). Sexual dimorphism with larger values for males than females was apparent in this trait. Therefore, this morphological trait could be taken into consideration as sexual trait determining the gender of adult birds.

This study has been unable to demonstrate that genotype effect was significant for the RA of middle toe length, the mean value being greater in the Quail Castellana Silver (5.23) than in the Black Menorca (1.17) and Red-Barred Vasca (1.15) genotypes until 8 wk of age (mixed sexes) in conventional system reported by Campo and Prieto (2009). Previous researchers suggested that middle toe length asymmetry was a sensitive indicator of stress. On the other hand, Campo et al. (2000) suggested that RA measures did not provide a general tool to indicate fearful or stress susceptibility in birds and utilization of FA as a biological monitor of environmental and genetic stress may be useful only in extreme conditions. Moreover Campo et al. (2007) determined that birds exposing to continuous light were more stressed and fearful according to the results of measured FA and TI. 
Campo and Prieto (2009) suggested that the utilization of FA, TI as biological indicators of well-being, fear, and stress may be not useful in all extreme conditions, especially in those including pain. On the other hand Møller et al. (1999) reported that FA was positively correlated with the duration of TI in chickens that were experiencing environmental stress. Hence, according to the current research findings, slow-growing broiler welfare indicators are similar to each other, resulted in an improvement in the greater the organic housing conditions.

Cholesterol and uric acid concentrations are ranged from 97.59 to $120.87 \mathrm{mg} / \mathrm{dL}$ and 3.67 to $5.56 \mathrm{mg} / \mathrm{dL}$ which are also in agreement with previous data reported by Silva et al. (2007) and Eleroğlu et al. (2011) who studied in conventional system.

In fact, it could be thought for the differences of serum level uric acid that GB-JA genotypes could not benefit more from dietary protein, although supplying the equally dietary protein level for two genotypes during rearing period and a study (Szabo et al., 2005) found a direct relation between the amount of ingested protein and uric acid serum level. Rajman et al. (2006) also found higher uric acid levels in broiler breeders during the rearing phase, at 30 and 44 days of age, as compared to older breeders.

Average Cholesterol levels was significantly $(\mathrm{P}<0.01)$ higher in male than in female slow-growing broiler (112.86 vs. 101.20). The higher values of cholesterol in S757 genotype correspond to their low mobilization by tissues and to their intense synthesis by the liver (Szabo et al., 2005). Furthermore, the increase of cholesterol value could be related to the higher dietary energy supply. The importance of biochemical parameters as diagnostic tools and physiological indicators in birds has been documented (Eleroğlu et al., 2011; Öztürk et al., 1999; Albokhadaim, 2012). However, these parameters are greatly affected by sex, age and season (Silva et al., 2007).

There is no significant correlation between overall TI and RT. This result is in agreement with these found by Campo et al. (2007) indicating that neither females nor males had significant correlation coefficients between morphological characters and TI. This result is in disagreement with these found by Ghareeb and Böhm (2008) indicating the ease of capture rank was negatively correlated with the TI at week 5 (-0.364) and with the NTI at week $6(-0.238)$ and suggested that birds TI and NTI had longer and higher.

Furthermore, the destitute of a strong correlation between the FA of other attributes showed that the level of FA in other attributes did not reverberate equally the quality of broilers. It is further known that the attributes could indicate high levels of genetic and phenotypic correlation in their means, notably morphological attributes between them and secondary sexual attributes between them, different attributes rarely showed much correlation in their level of FA (Campo et al., 2005a). On the contrary, Campo et al. (2000) analyzed that the correlation coefficient between mean RA of the different attributes and tonic immobility was positive and significant in the Villafranquina females $(r=0.32 ; \mathrm{P}<0.05)$, emphasized that hens with a high level of morphological FA tended to have a high level of fearfulness.

Results indicate that slow-growing genotypes and sex were not negatively affected by the measures of stress, such as the FA and RA, TI and RT. As can be seen from the results of other research that organic rearing conditions positively affects the welfare of both slow-growing genotypes. Moreover, further research would help to clearly define the relative importance of welfare indicators in organic rearing slow-growing broilers, which are exposed to several factors including infectious and parasitic diseases, social interactions, and adverse climatic conditions.

\section{ACKNOWLEDGEMENTS}

This study was supported by the Research Fund of Cumhuriyet University (Project No: ENF_003), which was approved by the local Ethical Committee of Cumhuriyet University for Experimental Animals.

\section{Author contributions}

E. H.: Designed the study, did the analysis, Y. A.: Wrote the article, D. M.: Made the application and Ş. A.: Corrected the article.

\section{REFERENCES}

Albokhadaim, I. 2012. Hematological and some biochemical values of indigenous chickens in Al-Ahsa, Saudi Arabia during summer season. Asian. J. Poult. Sci. 6: 138-145.

Bizeray, D. I., Estevez, C. Leterrier and J. M. Faure. 2002. Influence of increased environmental complexity on leg condition, performance, and level of fearfulness in broilers. Poult. Sci. 81: 767-773.

Campo, J. L. and M. T. Prieto. 2009. Associations among fluctuating asymmetry, duration of tonic immobility, heterophil-tolymphocyte ratio, and one-legged standing, crooked toes, or footpad dermatitis in chickens. Poult. Sci. 88: 65-71.

Campo, J. L., M. G. Gil, and S. G. Dávila. 2008. Effects of housing system and cold stress on heterophil-to-lymphocyte ratio, fluctuating asymmetry, and tonic immobility duration of chickens. Poult. Sci. 87: 621-626.

Campo, J. L., M. G. Gil, I. Muñoz and M. Alonso. 2000. Relationships between bilateral asymmetry and tonic immobility reaction or heterophil to lymphocyte ratio in five breeds of chickens. Poult. Sci. 79: 453-459. 
Campo, J. L., M. G. Gil, S. G. Dávila and I. Muñoz. 2005a. Estimation of heritability for fluctuating asymmetry in chickens by restricted maximum likelihood. Effects of age and sex. Poult. Sci. 84: 1689-1697.

Campo, J. L., M. G. Gil, S. G. Dávila and I. Muñoz. 2005b. Influence of perches and footpad dermatitis on tonic immobility and heterophil to lymphocyte ratio of chickens. Poult. Sci. 84: 10041009.

Campo, J. L., M. G. Gil, S. G. Dávila and I. Muñoz. 2007. Effect of lighting stress on fluctuating asymmetry, heterophil-tolymphocyte ratio, and tonic immobility duration in eleven breeds of chickens. Poult. Sci. 86: 37-45.

Dávila, S. G., J. L. Campo, M. G. Gil, M. T. Prieto and O. Torres. 2011. Effects of auditory and physical enrichment on 3 measurements of fear and stress (tonic immobility duration, heterophil to lymphocyte ratio, and fluctuating asymmetry) in several breeds of layer chicks. Poult. Sci. 90: 2459-2466.

Deeb, N. and A. Cahaner. 1999. The effects of naked neck genotypes, ambient temperature, and feeding status and their interactions on body temperature and performance of broilers. Poult. Sci. 78: 1341-1346.

Deeb, N. and A. Cahaner. 2001. Genotype-environment with broiler genotypes differing in growth rate. 1 . The effects of high ambient temperature and naked neck genotype on lines differing in genetic background. Poult. Sci. 80: 695-702.

Eleroğlu, H., A. Yıldırım, A. Şekeroğlu and M. Duman, 2014a. Comparison of the growth performance and carcass characteristics of two slow-growing broiler genotypes fed diets supplemented with dry oregano (Origanum vulgare L.) or lemon balm (Melissa officinalis L.) leaves under the organic system. Kafkas. Univ. Vet. Fak. Derg. 20: 49-58.

Eleroğlu, H., A. Yıldırım, N. D. Işıklı, A. Şekeroğlu, M. Duman. 2014b. Comparison of meat quality and fatty acid profile in slow-growing chicken genotypes fed diets supplemented with Origanum vulgare or Melissa officinalis leaves under the organic system under the organic system. Ital. J. Anim. Sci. 12: 395-403.

Eleroğlu, H., H. Yalçın and A. Yıldırım. 2011. Dietary effects of Ca-zeolite supplementation on some blood and tibial bone characteristics of broilers. S. Afr. J. Anim. Sci. 41: 319-330.

Ghareeb, K. and J. Böhm. 2008. Fear behaviour, ease of capture and performance traits of growing meat type chickens. Int. J. Poult. Sci. 7: 1185-1189.

Jones, R. B. and J. M. Faure. 1981. Sex and strain comparisons of tonic immobility ("righting time") in the domestic fowl and the effects of various methods of induction. Behav. Processes. 6: 47-55.

Lin, H., J. Buyse, R. Du, X. H. Gu and Z. Y. Zhang. 2004. Response of rectal temperature of broiler chickens to thermal environment factors. Arch. Für. Geflügelkunde. 68: 126-131.

Mendeş, M. 2008. Asymmetry measures and allometric growth parameter estimates for investigate effect of early feed restriction on deviation from bilateral symmetry in broiler chickens. Arch. Tierzucht. 51: 611-619.
Møller AP. 1992. Female swallow preference for symmetrical male sexual ornaments. Nature, 357: 238-240.

Møller, A. P., G. S. Sanotra and K. S. Vestergaard. 1995. Developmental stability in relation to population Gallus gallus. Poult. Sci. 74: 1761-1771.

Møller, A. P., G. S. Sanotra and K. S. Vestergaard. 1999. Developmental instability and light regime in chickens (Gallus gallus). Appl. Anim. Behav. Sci. 62: 57-71.

N'dria, A. L., S. Mignon-Grasteau, N. Sellier, C. Beaumont and M. Tixier-Boichard. 2007. Interactions between the naked neck gene, sex, and fluctuating ambient temperature on heat tolerance, growth, body composition, meat quality, and sensory analysis of slow growing meat-type broilers. Livest. Sci. 110: 33-45.

OFL. 2010. Organic Farming Legislation. Published by the Republic of Turkey Ministry of Food, Agriculture and Livestock. Turkey Official Gazette. 27676.

Öztürk, E., G. Erener and A. Yıldırım. 1999. Effects of sodium bicarbonate on the performance and some blood parameters of Japanese Quails in summer period. Turk. J. Vet. Anim. Sci. 23: 351-358.

Prieto, M. T. and J. L. Campo. 2010. Effect of heat and several additives related to stress levels on fluctuating asymmetry, heterophil: Lymphocyte ratio, and tonic immobility duration in White Leghorn chicks. Poult. Sci. 89: 2071-2077.

Rajman, M., M. Jurani, D. Lamosova, M. Macajova, M. Sedlackova, L. Kostal, D. Jesova and P. Vyboh. 2006. The effects of feed restriction on plasma biochemistry in growing meat type chickens (Gallus gallus). Comp. Biochem. Physiol. 145: 363-371.

Silva, P. R. L., O. C. Freitas Neto, A. C. Laurentiz, O. M. Junqueira and J. J. Fagliari. 2007. Blood serum components and serum protein test of hybro-PG broilers of different ages. Braz. J. Poult. Sci. 9: 229-232.

Szabo, A., M. Mezes, P. Horn, Z. Suto, G. Bazar and R. Romvari. 2005. Developmental dynamics of some blood biochemical parameters in the growing turkey (Meleagris Gallopavo). Acta. Vet. Hung. 53: 97-409.

Tuyttens, F., M. Heyndrickx, M. De Boeck, A. Moreels, A. Van Nuffel, E. Van Poucke, E. Van Coillie, S. Van Dongen and L. Lens. 2008. Broiler chicken health, welfare and fluctuating asymmetry in organic versus conventional production systems. Livest. Sci. 113: 123-132.

Van Nuffel, A., F. A. M. Tuyttens, S. Van Dongen, W. E. Talloen, E. Van Poucke, B. Sonck and L. Lens. 2007. Fluctuating asymmetry in broiler chickens: A decision protocol for trait selection in seven measuring methods. Poult. Sci. 86: 2555-2568.

Washburn, K. W., R. Peavey and G. M. Renwick. 1980. Relationship of strain variation and feed restriction to variation in blood pressure and response to heat stress. Poult. Sci. 59: 25862588.

Yang, A. 1998. Bilateral Asymmetry in Chickens of Different Genetic Backgrounds. The faculty of the Virginia Polytechnic Institute and State University, PhD. p.128, Thesis, Blacksburg, Virginia. 